\title{
The Role of Microsomal Galactose-tissues Specific Lectins from Prostate in Gland Peroxidation
}

\author{
Nino Kvitsinadze ${ }^{1}$, Elene Davitashvili ${ }^{1}{ }^{1 *}$, Maka Koshoridze ${ }^{1}$, Ketevan Chubinidze ${ }^{1}$, Nana Koshoridze ${ }^{1}$, \\ Mzia Goguadze $^{2}$, Omar Tsintsadze ${ }^{2}$, Guram Karazanashvili $^{3}$, Revaz Solomonia ${ }^{4}$ \\ ${ }^{1}$ Faculty of Exact and Natural Sciences, Department of Biology, I. Javakhishvili Tbilisi State University, Georgia \\ ${ }^{2}$ A. Tsulukidze Urology National Center, Pathomorphology Laboratory at the $1^{\text {st }}$ Clinical Hospital, Georgia \\ ${ }^{3}$ Clinic of SJC "Modern Medical Technologies", Georgia \\ ${ }^{4}$ Institute of Chemical Biology, Ilia State University, Georgia
}

Copyright $\bigcirc 2016$ by authors, all rights reserved. Authors agree that this article remains permanently open access under the terms of the Creative Commons Attribution License 4.0 International License

\begin{abstract}
Galactose-specific lectins are proteins with multifunctional properties, modulate cancerogenesis multistep process, and induce the remarkable generation of intracellular hydrogen peroxide. In this data we aim to investigate the effects of galactose-specific lectins isolated from the microsomal fraction of prostate post-operation tissues with different diagnosis in vitro model experiments (bovine liver tissue cells) on some aspects of peroxidation processes as one of the causes of tumor genesis. The beta-galactose-specific lectins were isolated from the microsomal fraction of prostate tissues with different diagnosis: benign prostate hyperplasia with low-grade intraepithelial neoplasia (BPH/LGPIN), high grade intraepithelial neoplasia (HGPIN), atypical adenomatous hyperplasia (AAH) and adenocarcinoma (PC). The molecular weight $(60 \mathrm{kDa})$ of lectins found to be similar, but their biological effects are different. The lectin from BPH/LGPIN tissue microsomes did not change the amount of malondyaldehyde (MDA), while the lectin from HGPIN, $\mathrm{AAH}$ and $\mathrm{PC}$ tissue microsomes induced increasing production of MDA. The lectins from all sources increase the amount of $\mathrm{H}_{2} \mathrm{O}_{2}$ in time-dependent manner. These effects are mediated by galactose binding domain of the lectins as are completely abolished by the inclusion of galactose. We proposed that one of the reasons of the revealed changes in the biological properties of lectins induced by alteration in the lectin's carbohydrate moiety structure. There is evidence that the changes of biological properties of prostate galactose-specific lectins are functionally related to development of the metabolic changes during prostate pathogenesis. In view of endoplasmic reticulum in many ways involved in carcinogenesis, we proposed the possible way, the released galactose-specific lectins from damaged microsomes enhances further transformation of prostate tissue by induction of MDA production and generation of free $\mathrm{H}_{2} \mathrm{O}_{2}$
\end{abstract}

Keywords Microsomal Lectins, Catalase, Lipid Peroxidation, Malondialdehyde, Prostate Gland Diseases

\section{Introduction}

Studies about physiological and biological properties of endogenous lectins have become a prominent issue in the recent years [1]. Lectins are nonimmune proteins that selectively recognize and reversibly binding to the terminal or subterminal carbohydrate determinants of glycoconjugates with no enzymatic activity; thus forming non-covalent bonds. Lectins participate in the regulation of many crucial biological processes, such as cell recognition, cellular differentiation, adhesion, signal transduction, embryogenesis, modulation of immune responses, fertilization, membrane transport, apoptosis, modulation of enzymatic activity, and cell division [2-4]. Number of endogenous and exogenous lectins promote synthesis of reactive oxygen species (ROS) [5-7]. Some of endogenous lectins are characterized by mitogenic activity and participate in tumor progression and metastasis $[8$, 9].Considering the fact that prostate cancer is the one of the most frequently diagnosed malignancy in males and the second leading cause of cancer-related death among men, our efforts have been concentrated on understanding the role of endogenous lectins from prostate tissue, in the progression of gland tumor [10]. There are three pathological changes affect prostate gland with highest frequency: inflammation (prostatitis), benign nodular enlargement (also termed $\mathrm{BPH}$ ) with low grade intraepithelial neoplasia (BPH/LGPIN), or with high grade intraepithelial neoplasia (HGPIN, precursor of prostate cancer), or with atypical adenomatous hyperplasia (AAH or adenosis) and adenocarcinoma (PC) $[11,12]$. The benign nodular enlargement and prostatic 
carcinoma are by far the most common among the above listed. Less information is available about the biochemical changes in the cells from tissues with HGPIN and AAH changes, as well as biological functions of the endogenous lectins in these processes. Adenosis - atypical adenomatous hyperplasia is one of the most common pseudoneoplastic lesions in the prostate that may be confused with adenocarcinoma because of its cytologic and architectural features [12]. Even though, the etiology of human prostate cancer is not well understood, oxidative stress has been identified as one of the causes of the development of prostate cancer. Relatively little is known about molecular events that underlie the development and progression of prostate cancer. Its' known that prostate cancer is a disease associated with aging and oxidative stress (a shift in prooxidant-antioxidant balance), which is also commonly associated with the age. The alteration of expression of three major antioxidant enzymes, copper-zinc superoxide dismutase (SOD1), manganese superoxide dismutase (SOD2), and catalase, was revealed by immunohistochemistry in human prostate carcinoma and in high grade prostatic intraepithelial neoplasia (HGPIN) [13]. The number of immunoreactive cells was greater in benign epithelium than in neoplasia and cancer.

Microsomes play a significant role in tumorigenesis by production of free radicals in prostate microsomes [14]. Several modes of action by which carcinogens induce cancer have been identified, including through production of ROS and oxidative damage to cellular macromolecules can arise through overproduction of ROS. Main biochemical reactions produce and scavenge ROS - superoxide radical $\left({ }^{\circ} \mathrm{O}_{2}^{-}\right)$, hidroxyl radical $((\mathrm{OH})$, singlet oxygen and hydrogen peroxide $\left(\mathrm{H}_{2} \mathrm{O}_{2}\right)$. The hydrogen peroxide is considered to be one of the most toxic ROS, however, is not highly reactive by itself. Superoxide dismutase reacts with the superoxide anion to form hydrogen peroxide and molecular oxygen and catalase converts hydrogen peroxide to water and molecular oxygen. Catalase is a very important enzyme in protecting cells from the accumulation of hydrogen peroxide and oxidative damage by ROS. The hydrogen peroxide is the most stable ROS. Intracellular generation of ROS, including of $\mathrm{H}_{2} \mathrm{O}_{2}$ has been considered an important mediator of apoptosis [15-17].

Lectins are one of the important chemical agents that induce ROS production and modulate cancerogenesis multistep process [16], they induce generation of large amount of intracellular hydrogen peroxide molecules at an early phase, thus resulting in apoptotic death of cancer cells. It has been well-known that beta-galactose-specific lectins (galectins) of the prostate gland play an important role in the transformation of human prostate [8,9]. The effects of galectins (-1 and -3$)$ is dependent on their distribution in cytoplasm, mitochondria and nucleus $[9,10]$. Unfortunately, there is less information about the microsomal lectins and their role in the prostate diseases. On one hand, a scarce data is available about the microsomal lectins in the liver [18] and the brain cells [19]. On the other hand, more information has been reported about the biological role of lectins isolated from the endoplasmic reticulum neoplasic and atypical tissue cells (calreticulin and calnexin) of prostate [20].

Take into consideration the afore-mentioned the aim of the present study was to purification and investigation of certain properties of microsomal galactose-specific lectins from tissues of men with BPH/LGPIN, HGPIN, AAH and PC diagnosis, their comparative analysis, and an investigation the role of prostate microsome galactose-specific lectins in vitro system on some aspects of peroxidation processes and hydrogen peroxide production.

And understanding of the role of prostate microsomal galactose-specific lectins in peroxidation processes.

\section{Materials and Methods}

\subsection{Materials}

Post-operational tissues have been obtained from: A.Tsulukidze Urology National Center, Pathomorphology Laboratory at the 1st Clinical Hospital and Clinic of SJC "Modern Medical Technologies". Human prostate tissue samples were obtained from patients undergoing open trans-abdominal prostatectomy for benign prostate hyperplasia and transurethral resection of the prostate (TURP). The cases with BPH/LGPIN diagnosis were $n=27$ (age 55-70 years), with HGPIN diagnosis $\mathrm{n}=15$ (age 50-68 years), with AAH diagnosis $n=20$ (age 50-75 years) and with $\mathrm{PC} n=9$ (age 54-67 years). Approval for the use of the tissues was obtained from the local ethical committee. After removal, pathological conditions were confirmed using histopathology. Diagnoses were draw according to the histopathological diagnostic criteria [21] by examining of the pre-operational needle biopsy samples and paraffin-embedded slices (post-operation). The cells in slices with AAH diagnosis had clear cytoplasm, and lacked malignant nuclear features; prominent nucleoli occurredin $21-25 \%$ of cases. The nuclear size and anisonucleosis were found to be the main features of the cells in the slices with BPH/LGPIN diagnosis.

Reagents: MDA was present in the lipid-peroxidation assay-kit from Calbiochem-Novabiochem Corporation Biosciences Company (Cat.No.437634); reagents for polyacrylamide gel-electrophoresis, agarose (for the affinity chromatography), TRIS and carbohydrates for study the carbohydrate specificity of lectins have been obtained from Sigma-Aldrich (Sigma-Aldrich Inc., St.Louis, USA).

\subsection{Isolation and Purification of Galactose-specific Lectins from the Microsomes of the Prostate Post-operational Tissue}

Galactose-specific lectins were isolated and purified from the microsomal fraction of human post-operation hyperplasic 
prostate tissues with following diagnoses: BPH/LGPIN, HGPIN, AAH and PC. Lectins were isolated from individual patient samples. Prostate epithelia and stroma were not separated from each other and a whole tissue has been used for the lectin purification. Microsomal fractions for lectin purification isolated from the human prostatic tissue as well as from the bovine liver according De-Robertis with differential centrifugation using sucrose density gradient. The purity of the microsomal fraction from the impurities of mitochondria was checked by measuring succinate dehydrogenase activity as the colored formazan product at the wavelength of $560 \mathrm{~nm}$ [22]. Microsomal fraction for the lectin isolation was treated with $0.5 \%$ detergent Triton-X-100 solution ( $40 \mathrm{mM} \mathrm{KH} \mathrm{PO}_{4}, 0.15 \mathrm{M} \mathrm{NaCl}, \mathrm{pH}$ 7.4 containing a cocktail of protease inhibitors). Extract was centrifuged at 20,000 $\mathrm{g}$ for $30 \mathrm{~min}$, supernatant was collected and saturated by ammonium sulfate ( $80 \%$ saturation). The precipitates were collected by centrifugation at $12,000 \mathrm{~g}$ for $20 \mathrm{~min}$, re-dissolved in a minimal volume of extraction buffer, dialyzed overnight against the PBS at $4{ }^{\circ} \mathrm{C}$ and centrifuged at 12,000 $\mathrm{g}$ for $15 \mathrm{~min}$. The galactose-specific lectins purified by affinity chromatography (agarose sorbent), eluted with $0.2 \mathrm{M}$ galactose. The purity of lectins was checked by sodium dodecylsulfate (SDS) polyacrylamide gel-electrophoresis (10\% PAGE) according to Laemmli [23]. Protein concentration was measured by Protein Assay Kit (Sigma, USA), according to the manufacturer's protocol. Assay for Hemagglutination Activity was carried out as described in our recent work [24]. The hemagglutination titre, defined as the reciprocal of the lectin solution highest dilution exhibiting hemagglutination, was reckoned as one hemagglutination unit (HA U). Specific activity is the number of the hemagglutination units per mg protein (HA $\mathrm{U} / \mathrm{mg}$ protein).

Effects of purified galactose-specific lectins in vitro systems were investigated on bovine microsomal properties. The following biochemical parameters were studied: malondialdehyde concentration as product of lipid peroxidation, catalase activity and generation of free $\mathrm{H}_{2} \mathrm{O}_{2}$. Five types of the samples have been used in all experiments: (1) containing only incubation medium with bovine microsomal fraction; (2) with the addition of lectin (total concentration $5 \mu \mathrm{g} / \mathrm{ml}$ ) from tissue microsomes (BPH/LGPIN, HGPIN AAH and PAC); (3) with the addition of the lectin (total concentration $5 \mu \mathrm{g} / \mathrm{ml} / \mathrm{ml}$ ) from tissue microsomes (of all diagnoses), (4) addition the pre-incubating lectins with their corresponding specific inhibiting sugar (at a concentration of $0.2 \mathrm{M}$ galactose) for 30 min before applying to the incubation area and (5) with the addition of $0.2 \mathrm{M}$ galactose. All types of the samples (see above) were preliminary incubated with other components depending on the sample types at $37^{\circ} \mathrm{C}$ for $60 \mathrm{~min}$.

\subsection{Lipid Peroxidation Assays}

The lipid peroxidation was estimated by measuring of final product - MDA concentrations. MDA concentration was assessed with a colorimetric method by Lipid peroxidation assay kit (Calbiochem-Novabiochem Corporation Biosciences Company, Cat.No.437634), according to the manufacturer's protocol. Amount of MDA was determined by the reaction with $\mathrm{N}$-acetyl-2-phenylindol e. MDA concentrations were determined from a standard curve of malondialdehyde bis-(dimethyl acetal) and reported at $\mu \mathrm{M} \mathrm{MDA} / \mathrm{mg}$ protein. The absorbance of MDA was measured by Multiscan GO Microplate Reader (Thermo Scientific, USA) at $586 \mathrm{~nm}$ wavelength.

\subsection{Determination of Catalase Activity}

The catalase activity was determined by modified method [20]. The method was based on the ability of hydrogen peroxide to form a colored complex with salts of molybdenum. The absorbance of the obtained supernatant (A test) was measured against control $\left(\mathrm{H}_{2} \mathrm{O}+\right.$ ammonium molybdate) by Multiscan GO Microplate Reader (Thermo Scientific, USA) at $410 \mathrm{~nm}$ wavelength. The catalase activity was expressed $\left(\mathrm{A}_{\mathrm{H}_{2} \mathrm{O}_{2}}-\mathrm{A}\right.$ test $)$ in $\mu \mathrm{M}$ of $\mathrm{H}_{2} \mathrm{O}_{2}$ per mg of protein per 1 minute, $\mathrm{A}_{\mathrm{H}_{2} \mathrm{O}_{2}}-$ means the absorbance, measured for $\mathrm{H}_{2} \mathrm{O}_{2}$ (reaction between $0.03 \% \mathrm{H}_{2} \mathrm{O}_{2}$ and ammonium molybdate). Determination of free $\mathrm{H}_{2} \mathrm{O}_{2}$ was studied in a time dependent fashion (after 1, 15, 30, 60 min of incubation). Amount of free $\mathrm{H}_{2} \mathrm{O}_{2}$ was determined by a reaction with ammonium molybdate (absorbance at $410 \mathrm{~nm}$ wavelength) [20]. The amount of free $\mathrm{H}_{2} \mathrm{O}_{2}$ was expressed in $\mu \mathrm{M}$ of $\mathrm{H}_{2} \mathrm{O}_{2}$ per mg of protein per $1 \mathrm{~min}$.

\subsection{Data Analysis}

The specific lectin activity data of galactose-specific lectins, isolated from prostate tissue microsomes with BPH/LGPIN, HGPIN AAH and PC diagnoses were evaluated by Student's $t$-test. A level of $p<0,05$ was accepted as an indication of statistical significance. For the evaluation of influence of galactose-specific lectins from different pathological tissues on the lipid peroxidation and catalase activity data were treated with one-way ANOVA (factor - different sample type). For the evaluation of the influence of incubation time on the in control groups (samples with addition only of buffer and lectin with $0.2 \mathrm{M}$ galactose) data were treated with one-way ANOVA also (Factor - time of incubation). For the evaluation of lectins effects and time of incubation on the free $\mathrm{H}_{2} \mathrm{O}_{2}$ generation, two-way ANOVA was applied (factors: time of incubation and source of lectin).

\section{Results}

The purified galactose-specific lectins from prostate microsomes with BPH/LGPIN, HGPIN, AAH and PC diagnoses migrated as a single band with an apparent 
molecular weight of $60 \mathrm{kDa}$ (Fig. 1). All the lectins tested proved positive to the Schiff's reagent, which indicate to their glycoprotein nature.

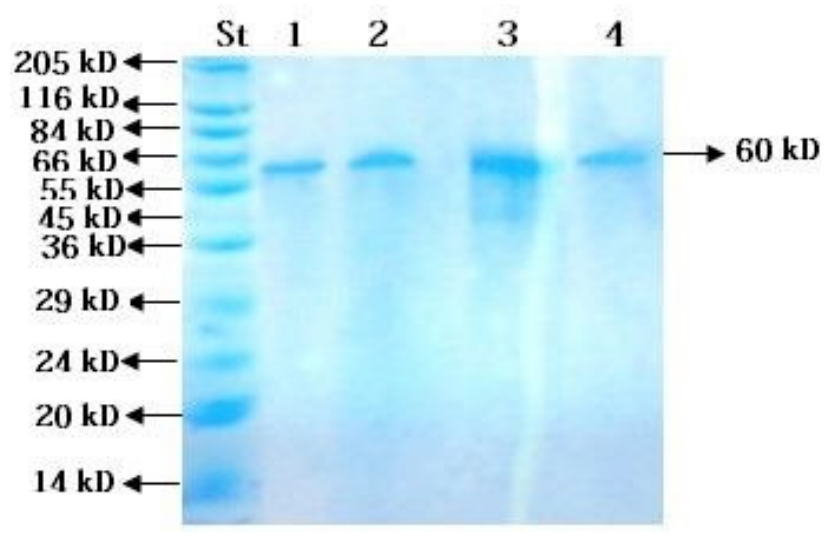

Figure 1. SDS-gel electrophoresis (10\% PAGE) of microsomal lectins isolated from individual patient sampes: BPH/ LGPIN (line 1, $n=7$ ), HGPIN (line 2, n=7), AAH (line 3, n=7), ) and PC (line 4, n=5) diagnosed prostate tissues. Positions of the protein molecular weight standards are indicated on the left side of the gel.

The hemagglutination (specific) activity of galactose-specific lectins, isolated from prostate tissue microsomes with BPH/LGPIN, HGPIN, AAH and PC diagnoses correlates with progression of disease (Fig. 2). The specific activity of galactose-specific lectins from AAH and PC microsomes was increased $(6160 \pm \mathbf{5 8 0}$ and $9750 \pm \mathbf{2 8 5}$ accordingly, $\mathrm{p}<0.01$ ), compared with the galactose-specific lectins activity from BPH/LGPIN (1561 $\mathbf{3 5 5})$.

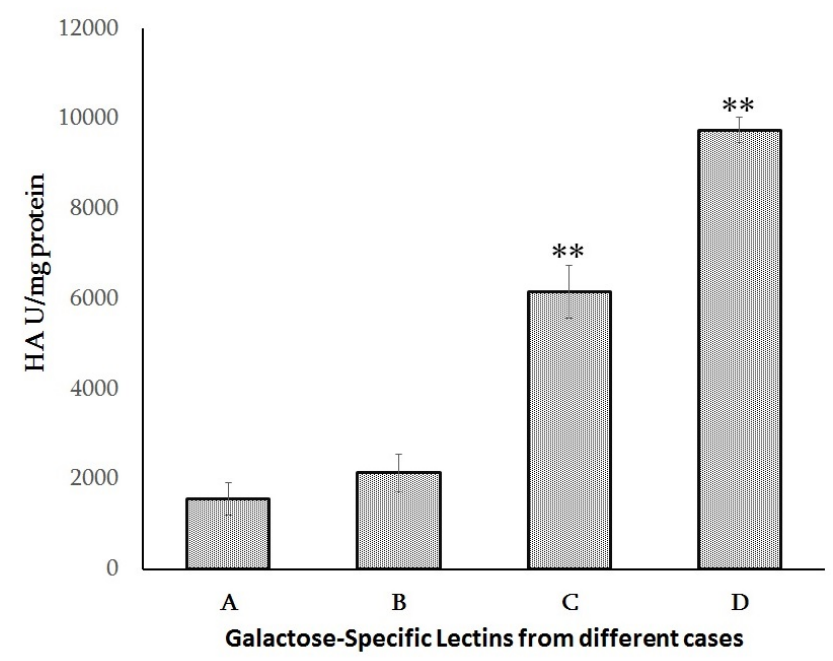

Figure 2. Changes in the specific activity (SA) of microsomal galactose-specific lectins, isolated and purified from the microsomal fraction of BPH/LGPIN (A, n=27), HGPIN (B, n=15), AAH (C, n=20) and PC $(D, n=9)$ diagnosed prostate tissues. Data are expressed as a Hemagglutination Units (HA U) $/ \mathrm{mg}$ protein, compared to the SA of galactose-specific lectin from BPH/ LGPIN diagnosed tissue microsome. Error bars represent $\pm \mathrm{SEM}, * * p<0.01$.
The influence of the microsomal galactose-specific lectins (5 $\mu \mathrm{g} / \mathrm{ml}$ ) from BPH/LGPIN, HGPIN, AAH and PC diagnosed tissues were studied in vitro systems following the preliminary incubation of lectins with the bovine microsomal fraction (at $37^{\circ} \mathrm{C}$, for $60 \mathrm{~min}$ ) (Fig. 3). Influence of lectins on the lipid peroxidation revealed the differences between the studied lectins. The amount of MDA did not increase significantly under the influence of microsomal lectin from the BPH/LGPIN diagnosed tissue in comparison with the control. The same result was obtained when galactose (final concentration of $0.2 \mathrm{M}$ ) was added together with lectin. In contrast, the microsomal lectins from HGPIN $(0.43 \pm 0,051$, $\mathrm{p}<0.01)$, AAH $(0,375 \pm 0,025, \mathrm{p}<0.05)$ and PC $(0.42 \pm 0,038$, $p<0.01)$ diagnosed tissue revealed the significant effect on the lipid peroxidation, the amount of MDA was increased accordingly against the control $(0,295 \pm 0.0221)$. The effect of lectins has been diminished by pre-incubating the certain ones with $0.2 \mathrm{M}$ Galactose (see Methods, sect. 2.2) prior to MDA assay, thus there was no significant difference between control and experimental groups' MDA level. However, the addition of just the $0.2 \mathrm{M}$ galactose to the incubation medium has no impact on generation of MDA in microsomal fraction (data isn't presented).

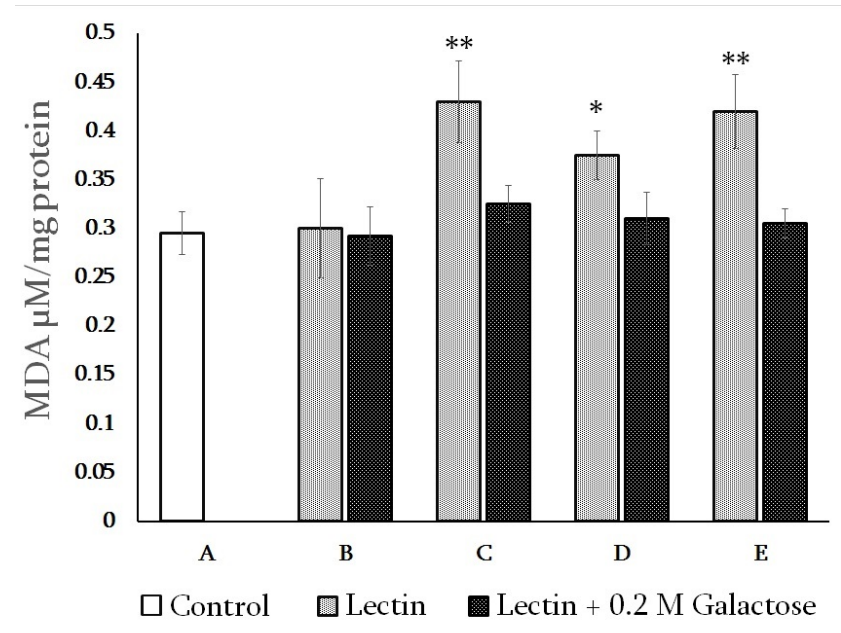

Figure 3. Influence of galactose-specific lectins, isolated and purified from the microsomal fraction of BPH/LGPIN (B, n=20), HGPIN (C, n=12), AAH (D, n=12) and PC (E, n=7) diagnosed prostate tissues on microsomal malondialdehyde (MDA) concentration of bovine liver cells compared with untreated ones ( $\mathrm{A}, \mathrm{n}=20$ ). Data present mean \pm SEM. ${ }^{*} p<0.05,{ }^{* *} p<0.01$

Catalase activity (Fig. 4) was significantly increased under the influence of microsomal lectins from BPH/LGPIN $(20,05 \pm \mathbf{0 , 9}, p<0,05)$, HGPIN $(21,05 \pm \mathbf{0}, \mathbf{8 1}, p<0,05)$, AAH $(22,7 \pm \mathbf{0}, \mathbf{5}, p<0,01)$ and $\mathrm{PC}(22,05 \pm \mathbf{0 , 4 5}, p<0,01)$ diagnosed tissues as compared to the control (bovine liver microsomal fraction, $15,5 \pm \mathbf{1 , 2}$ ). The addition of galactose (total concentration of $0.2 \mathrm{M}$ ) in incubation area prevented the effect of lectins. 


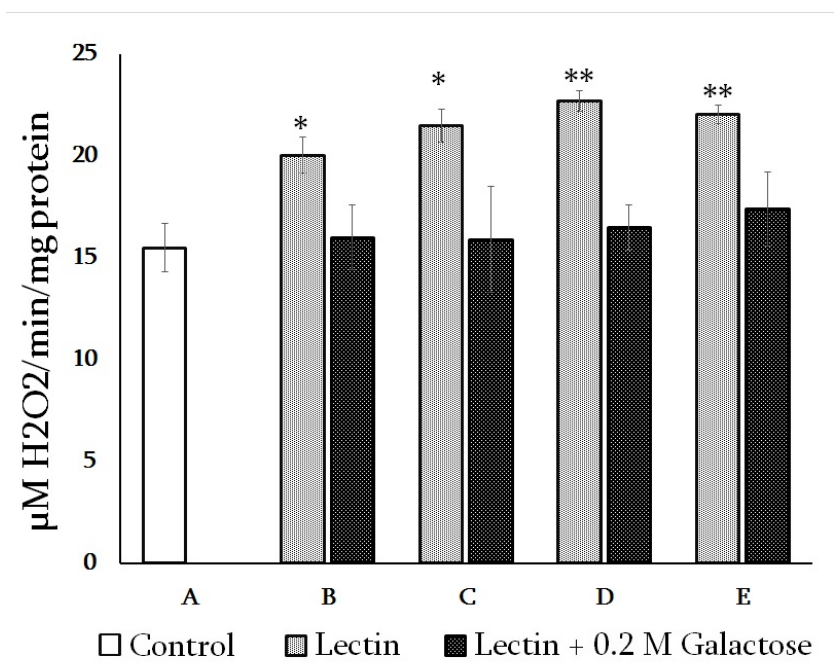

Figure 4. Influence of galactose-specific lectins, isolated and purified from the microsomal fraction of human post-operational BPH/LGPIN (B, $\mathrm{n}=20)$, HGPIN $(\mathrm{C}, \mathrm{n}=12)$, AAH $(\mathrm{D}, \mathrm{n}=12)$ and PC $(\mathrm{E}, \mathrm{n}=7)$ diagnosed prostate tissues on the bovine liver cells' microsomal catalase activity in contrast with untreated ones $(\mathrm{A}, \mathrm{n}=20)$. Data present mean \pm SEM. $* p<0.05$, $* * p<0.01$.

The amount of $\mathrm{H}_{2} \mathrm{O}_{2}$ did not change significantly in the controls over time (Fig. 5). The same results were obtained when galactose was added together with lectins in a total concentration of $0.2 \mathrm{M}(p>0.05)$. Incubation the bovine liver cells with lectins (without of galactose) produced a significant effect only for time factor. 15 Min incubation with lectins did not reveal significant changes as compared with $1 \mathrm{~min}$ incubation (BPH/LGPIN, $p>0.05$; HGPIN, $p>$ 0.05; $\mathrm{AAH}, p>0.05$; $\mathrm{PC}, p>0.05)$.

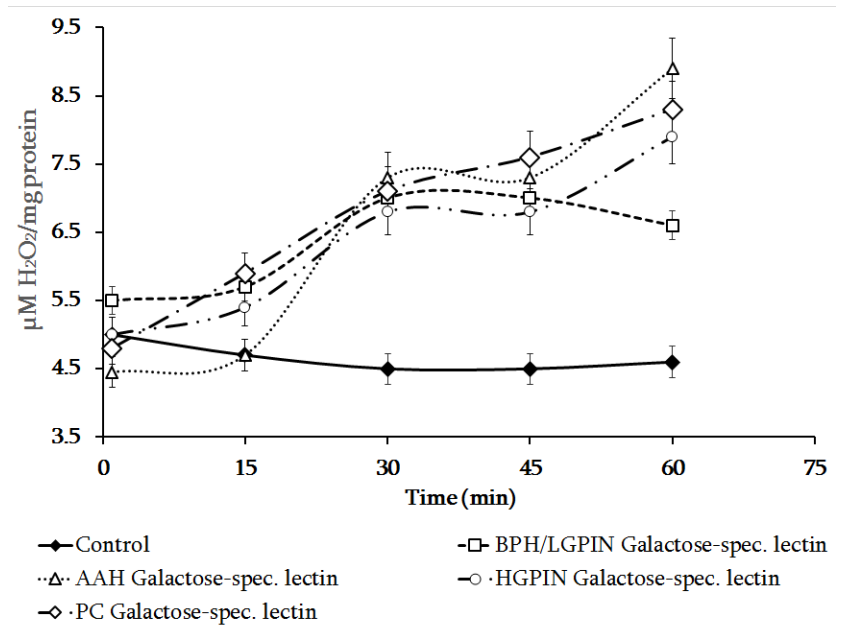

Figure 5. Time-dependent changes in the amount of microsomal $\mathrm{H}_{2} \mathrm{O}_{2}$ in bovine liver cells incubated with galactose-specific lectins, isolated and purified from prostate tissue microsomes with different diagnosed (BPH/LGPIN $n=20$, HGPIN $n=12$, AAH $n=12$ and PC $n=7$ cases) compared to untreated bovine liver cells (control). Data present mean \pm SEM.

After an additional $15 \mathrm{~min}$ of incubation $(30 \mathrm{~min}$ from the starting point) a significant increase was observed for lectins compared to the mean value at $1-$ min (BPH/LGPIN $-28 \%, p$
$<0,05$; HGPIN- 34\%, p $<0.01$; AAH- $63 \%, p<0,01$ and $\mathrm{PC}-55 \%, p<0,01)$. At $60 \mathrm{~min}$ of incubation further significant increases of the amount of $\mathrm{H}_{2} \mathrm{O}_{2}$ was demonstrated under the influence of microsomal lectin from AAH, HGPIN and PC diagnosed tissue to compared with previous time point (30 min mean value, $22 \%, 10 \%$ and $13 \%$ accordingly), whereas the same comparison for a microsomal lectin from BPH/LGPIN diagnosed tissue did not reveal significant changes $(p>0.05)$, but was still higher compared with the $1-$ min mean value $(21 \%$,). These results indicated that microsomal galactose-specific lectin from AAH diagnosed tissues induced a significantly greater increase of $\mathrm{H}_{2} \mathrm{O}_{2}$ production compared with the lectin from HGPIN and PC diagnosed tissue at 60 min of incubation.

\section{Discussion}

Lectins are found in various organisms, they widely distribution in plants, animals, bacteria, viruses, mushrooms. These proteins can be detected through haemagglutination assays, interact with different carbohydrates present in cell surfaces. Depending on their properties and distribution in tissues, lectins can play important physiological roles [26]. Lectins have already been shown to exhibit different biological activities and effects, such as mitogenic and antiproliferative activities on cell lines of human cancer, inhibition of bacterial and fungal growth, action as promoting agents in cell aggregation, immunomodulatory activities and toxic effects. Lectins are known to influence cell growth in several types of normal and neoplastic tissues. However, their role in prostatic cancer cells remains relatively unexplored. Most of the studies on prostatic cells have concentrated on understanding the biological properties of Galectins that play an important role in transformation of gland cells [2-4,8,26,27], Galectins are characterized by a variety of activites and participate in many important processes including proliferation, metastasis, differentiation and apoptosis [1,9,27-28], and lipid peroxidation [5-7]. Lipid peroxidation is implicated in the pathogenesis of numerous diseases. In prostate cancer oxidative stress, an innate key event characterized by generation of high concentrations of ROS, has been identified as one of the hallmarks of the aggressive disease phenotype [14, 29-30]. Sources of cellular ROS are the microsomes, peroxisomes and mitochondria. Furthermore, the lectins induced the hydrogen peroxide generation [5-6, 16]. However, there is a limited information available on the biological function of prostate lectins, isolated from microsomal fractions with HGPIN and AAH diagnoses and their role in oxidation/peroxidation processes. So the main goal of our study was to invastigate the role of galactose-specific lectins on peroxidation/oxidati on pathways. In previous study [31] the galactose-, mannose-, glucose- and $\mathrm{N}$-acetylglucosamine-specific lectins had been found in prostate tissue microsomal fraction from different cases. Our attention has been 
concentrated on the research of galactose-specific lectins, while considering the below mentioned terms.

First, it has been revealed that there are subtle differences in glycosylation of protein between normal prostatic tissues cells and those from BPH and Prostatic carcinoma. The cells from prostatic carcinoma tissues are characterized by the expression of proteins with galactose residues [32-33]. Second, among the multiple properties of galactose-specific lectins is their involvement in lipid peroxidation processes [6, 7], were they play an active role in carcinogenesis.

Obtained data indicate that prostate tissue microsomes contain the beta-galactose-specific lectins, whose specific activity is changed depending on the diagnosis of tissue specimen. The molecular weights of isolated lectins $(60 \mathrm{kDa})$ differ from that of known galectins (not more than $36 \mathrm{kDa}$, only the galectin-9 molecular weight is about $50 \mathrm{kDa}$ ) [17].

The alteration of MDA levels, as a result of actions of microsomal lectins, indicates that lectins are involved in the peroxidation processes in microsomes. Depending on the source of lectins (tissues with different diagnoses), their biological effects on peroxidation processes also vary. Galactose-specific lectin from HGPIN, AAH and PC tissue microsomes revealed a significant biological effect. These lectins enhanced MDA production in bovine liver cells microsomes in vitro. Lectins from BPH/LGPIN tissue microsomes had no such effect. From the results it was established that galactose-specific lectins from BPH/LGPIN diagnosed tissue microsomes enhanced the catalase activity, but the long incubation (60 min) periods and other lectins [16] induced the hydrogen peroxide generation. The galactose-sp ecific lectins from HGPIN, AAH and PC tissue microsomes have a time-dependent effect on the production of $\mathrm{H}_{2} \mathrm{O}_{2}$. However, in comparison with that in BPH/LGPIN tissues, $\mathrm{AAH}$ and $\mathrm{PC}$ tissue lectins induce more intensive generation of $\mathrm{H}_{2} \mathrm{O}_{2}$. It is noteworthy that increasing intensity of peroxidation processes causes increased activity of catalase, which is an indirect effect of lectins on the activity of catalases. Considering the fact that ROS are significant factors for initiation of neoplastic growth [14] the regulation of $\mathrm{H}_{2} \mathrm{O}_{2}$ concentration is of great importance in functioning of normal cells.

The effects of lectins are mediated by carbohydrate binding domains of lectins. Glycosylation is one of the most common co- or posttranslational modifications. The addition of lectin, pre-incubated with galactose completely abolished this effect. Despite identical molecular weights of galactose-specific lectins from microsomes, of tissues with different diagnoses, different biological activities have been revealed. The effect might be caused by the difference in carbohydrate moieties of lectins. There is limited information available on carbohydrate components in catalase molecules, except those from fungal organisms and their glycosylation during hyperglycemia [34]. Therefore, at this stage it is difficult to make any conclusions about interaction of lectins with enzyme molecules.

Similar results were revealed with mitochondrial lectins purified from hyperplasic prostate tissue with BPH/LGPIN and AAH diagnosis [35]. The molecular weights of isolated mitochondrial galactose-specific lectins are also equal to that of microsomal lectins $(60 \mathrm{kDa})$. Mitochondrial and microsomal galactose-specific lectins isolated from tissues with AAH diagnosed induced stronger peroxidation that did mitochondrial and microsomal lectins, isolated from tissues with BPH/LGPIN. On the other hand, they both equally enhance the production of $\mathrm{H}_{2} \mathrm{O}_{2}$. The galactose-specific lectins isolated from prostate tissue mitochondria and microsomes also revealed the different dependences toward the bivalent ions. The hemagglutination activity of microsomal lectins isolated from prostate tissue (BPH/LGPIN, HGPIN, AAH and PC diagnosis tissue) was inhibited by $\mathrm{Ca}^{2+}$ ions. On the other hand, $\mathrm{Ca}^{2+}$ ions had no effect on mitochondrial lectins [36]. We have ensured the clarity sub-cellular fractions considering the accuracy of the isolation method by the determination of the enzyme succinat dehydrogenase activity [22]. The afore-mentioned excludes possibility that microsomes and mitochondrial lectins are identical.

Furthermore, the molecular mechanism of the influence of lectins on lipid peroxidation is still unclear. Studies of the biological functions of galactose-specific lectins are very important for biochemical research, for disease diagnosis and clinical intervention. The histochemical study of the lectins with different carbohydrate-specificity revealed the altered expression of glycoconjugates and increased expression of galactoside-galactosamine residues in early premalignant stage of prostate $[27,37,38]$. The effect of lectins was revealed in vitro, after incubation with microsomes from bovine liver cells. In previous studies, micrsomes from tissues with HGPIN, AAH and PC have shown an increased lipid peroxidation (malondialdehyde concentration) in comparison with the microsomes from BPH [39]. It's known that glycoprotein metabolism is altered in malignancies [27, 33]. Under intensified peroxidation processes that take place during the transformation, oxidative stress might be responsible for alteration in glycosylation of proteins, which is one of the important molecular changes that accompany malignant transformation [38]. It is probable that the changes in biological properties of the lectins isolated from microsomes of tissues with different diagnosis is caused by the changes in the carbohydrate moiety of the lectins' structure.

In view of endoplasmic reticulum in many ways involved in carcinogenesis [40], we proposed that microsomes dysfunction and damage could lead to the release of microsomal lectin, which binds with glycoconjugates on the undamaged sites of reticulum, induces the hydrogen peroxidation generation and further oxidative stress. There is evidence that the changes of biological properties of prostate galactose-specific lectins are functionally related to development of the metabolic changes during prostate pathogenesis 


\section{Conclusions}

There was studied the biological properties of galactose-specific lectins, isolated from prostate tissue with different diagnoses (BPH/LGPIN, HGPIN, AAH and PC) in vitro system (bovine liver cells microsomes). The lectins have similar molecular weight, but depending on the source of lectins (tissue diagnose), their biological effects on peroxidation processes also vary. The galactose-specific lectins from $\mathrm{AAH}$ and PC diagnosed tissue microsomes revealed a significant biological effect on microsomal MDA production in vitro system. The addition of galactose completely abolished this effect.

Thus we conclude that: 1) abnormally high lipid peroxidation and the generation of $\mathrm{H}_{2} \mathrm{O}_{2}$ involve the pathogenesis of prostate gland 2) the changes of biological properties of prostate galactose-specific lectins are functionally related to development of the metabolic changes during prostate pathogenesis 3) one of the reasons of the revealed changes in the biological properties of microsomal galactose-specific lectins can be induced by alteration in glycosylation of the lectin carbohydrate moiety and 4) one more additional mechanism of prostate tissue neoplasic transformation includes the following: microsomes dysfunction and damage could lead to the release of microsomal lectin, which acts on the normal sites of reticulum, induces the hydrogen peroxidation generation and further oxidative stress.

\section{REFERENCES}

[1] Nakahara S, Raz A. Biological Modulation by Lectins and Their Ligands in Tumor Progression and Metastasis Anticancer Agents Med Chem, 8(1): 22-36, 2008.

[2] Gabius H, Andre S, Kaltner H, Siebert H. The sugar code: functional lectinomics. Biochim Biophys Acta, 1572: 165-177, 2002.

[3] Varki A, Cummings R, Esko J, Freeze H, Stanley P, Bertozzi C, Hart G, Etzler M. Essentials of Glycobiology.2nd ed. Cold Spring Harbor Laboratory Press, Cold Spring Harbor, New York; 2008.

[4] Solis D, Bovin N, Davis A, Jiménez-Barbero J, Romero A, Roy R, Smetana K, Gabius H. A guide into glycosciences: How chemistry, biochemistry and biology cooperate to crack the sugar code. Biochim Biophys Acta, 1850(1): 186-235, 2015.

[5] Timoshenko AV, Kayser K, Drings P, Kolb G, Havemann K, Gabius HJ. Modulation of lectin-triggered superoxide release from neutrophils of tumor patients with and without chemotherapy. Anticancer Res, 13: 1789-1792, 1993.

[6] Elola MT, Fink NE. Different galectins can stimulate superoxide production in human neutrophils. E-Lectin $\mathrm{J}$ Lectins Biol Biochem Clin Biochem, 13: 154-9, 2000.
[7] Kvitsinadze N, Kapanadze E, Tsinadze N, Davitashvili E, Solomonia R, Aleksidze N. Influence of galactose-specific lectin isolated from Coriander on the lipid peroxidation in the liver cells and erythrocytes. Bull Georg Acad. Sci., 167(3): 521-523, 2003.

[8] Liu F, Rabinovich G. Galectins as modulators of tumour progression. Nat Rev Cancer, 5: 29-41, 2005.

[9] Van den Brule F, Waltregny D, Liu F, Castronovo V. Alteration of the cytoplasmic/ nuclear expression pattern of galectin-3 correlates with prostate carcinoma progression. Int $\mathrm{J}$ Cancer, 89: 361-7, 2000.

[10] Ahmed H, Banerjee P, Vasta G. Differential expression of galectins in normal, benign and malignant prostate epithelial cells: silencing of galectin-3 expression in prostate cancer by its promoter methylation. Biochem Biophys Res Commun, 358: 241-6, 2007.

[11]Zynger DL, Yang X. High-grade prostatic intraepithelial neoplasia of the prostate: the precursor lesion of prostate cancer. Int J Clin Exp Pathol, 2: 327-338, 2009.

[12] Baydar DE. Adenosis (Atypical Adenomatous Hyperplasia) of Prostate. J Urol Surgery, 1: 53-54, 2015. doi: 10.4274/jus.2015.01.018.

[13] Bostwick D,. Alexander E, Singh R, Shan A, Qian J et al.Antioxidant enzyme expression and reactive oxygen species damage in prostatic intraepithelial neoplasia and cancer. Cancer, 89 (11):123-134, 2000.

[14]Kumar B, Koul S, Khandrika L, Meacham R, Koul H. Oxidative Stress Is Inherent in Prostate Cancer Cells and Is Required for Aggressive Phenotype. Cancer Res, 68: 1777-85, 2008.

[15] Yang L1, Zheng XL, Sun H, Zhong YJ, Wang Q, He HN et al.Catalase suppression-mediated $\mathrm{H}(2) \mathrm{O}(2)$ accumulation in cancer cells by wogonin effectively blocks tumor necrosis factor-induced NF-kB activation and sensitizes apoptosis. Cancer Sci, 102(4):870-6, 2011.

[16] Kim MS , Lee J ,Lee KM ,Yang SH, Choi S et al. Involvement of hydrogen peroxide in mistletoe lectin-II-induced apoptosis of myeloleukemic U937 cells. Life Sciences, 73(10):1231-1243, 2003.

[17] Klaunig J, Kamendulis L, Hocevar B. Oxidative Stress and Oxidative Damage in Carcinogenesis. Toxicologic Pathology, 38 (1): 9-109, 2010.

[18] Maynard Yv, Baenziger J. Characterization of a Mannose and N-Acetylglucosamine-specific Lectin Present in Rat Hepatocytes. J Biol Chem, 257(7): 3788-3794, 1982.

[19] Koshoridze N, Aleksidze N, Surguladze N. Inositol- and galactose binding lectins from chicken brain fractions enriched with glial cells. Zh Evol Biokhim Fiziol (Russ) 2003; 39(4):356-9.

[20] Williams D. Beyond lectins: the calnexin/calreticulin chaperone system of the endoplasmic reticulum. J Cell Sci, 119(Pt4): 615-623, 2006.

[21] Tadros JP. Diagnostic Criteria Handbook in Histopathology. A surgical Pathology Vade Mecum. 2007; 422 p. John Wiley\&Sons, LTD. 
[22] Kuchukashvili Z, Menabde K, Chachua M, Burjanadze G, Chipashvili M, Koshoridze N. Functional state of rat cardiomyocytes and blood antioxidant system under psycho-emotional stress. Acta biochim biophys Sin, 43 (6): 480-486, 2011.

[23] Laemmli UK. Cleavage of structural proteins during the assembly of the head of bacteriophage T4. Nature, 227(5259): 680-685, 1970.

[24] Davitashvili E, Kapanadze E, Kachishvili E, Metreveli E, Elisashvili V. Comparative Study of the Hemagglutinating Activity of Lectins Isolated from Different Developmental Stages of Culinary-Medicinal Oyster Mushroom, Pleurotus ostreatus (Jacq.: Fr.) Kumm. (Agaricomycetideae) Int $\mathrm{J}$ of Medicin Mushrooms, 12(Is.1): 43-50, 2010.

[25] Aebi H. Catalase in vitro. Methods Enzymol, 105: 121-6, 1984.

[26]N. Sharon, "Lectins: carbohydrate-specific reagents and biological recognition molecules," The Journal of Biological Chemistry, 282(5): 2753-2764, 2007.

[27] Gorelik E, Galili U, Raz A. On the role of cell surface carbohydrates and their binding proteins (lectins) in tumor metastasis. Cancer Metastasis Rev, 20: 245-277, 2001.

[28] Breitenbach LC, in book: Current Topics in Peptide \& Protein Research, Chapter: Lectins: Function, structure, biological properties and potential applications, Publisher: Research Trends, 15:41-62, 2015

[29] Aydin A. Arsova-Sarafinovska Z, Sayal A. Oxidative stress and antioxidant status in non-metastatic prostate cancer and benign prostatic hyperplasia. Clin Biochem, 39: 176-9, 2006.

[30] Ray PD1, Huang BW, Tsuji Y. Reactive oxygen species (ROS) homeostasis and redox regulation in cellular signaling. Cell Signal. 2012 May; 24(5): 981-90. doi: 10.1016/j.cellsig.2 012.01.008. Epub 2012 Jan 20.

[31] Kvitsinadze N, Muradashvili M, Davitashvili E, Solomonia R, Alexidze G, Karazanashvili G, Tsintsandze O, Managadze L, Aleksidze N. Isolation and characterization of proteins with lectin activity from prostate fiber-muscular tissue at different pathologies. Bull Georg Acad Sci, 169(2): 360-362, 2004.
[32] Dabelsteen E. Cell surface carbohydrates as prognostic markers in human carcinomas. The Journal of Pathology, 179 (Is4):358-369, 1996.

[33] Arenas M., Romo E, de Gaspar I, de Bethencourt F, Sánchez-Chapado M, Fraile B, Paniagua R. A lectin histochemistry comparative study in human normal prostate, benign prostatic hyperplasia, and prostatic carcinoma. Glycoconj J, 16(7): 375-82, 1999.

[34] Wang H, Tokusige Y, Shinoyama H, Fujii T, Urakami T. Purification and characterization of a thermostable catalase from culture broth of Thermoascus aurantiacus. J Ferment Bioeng, 85(Is2): 169-173, 1998.

[35] Davitashvili1 E, Kvitsinadze N, Megrelishvili I, Karazanashvili G, Solomonia R, Aleksidze N. Influence of beta-galactose-specific mitochondrial lectins from prostate hyperplasic tissue on mitochondrial properties. Scand J Clin Labor Invest, 70(1):33-39, 2010.

[36] Kvitsinadze N, Megrelishvi Iv, Davitashvili E, Solomonia R, Aleksidze N, Karazanashvili G. The study of divalent cations influence on the hemagglutination activity of lectin from subcellular fractions of a prostate in various pathologies. Proceed. Georg.Acad.Sci, Ser.B, 4(2): 5-7, 2006.

[37] Chan F, Choi H, Ho S. Analysis of glycoconjugate patterns of normal and hormone-induced dysplastic Noble rat prostates, and an androgen-independent Noble rat prostate tumor, by lectin histochemistry and protein blotting. The Prostate, 46(1): 21-32, 2001.

[38] Valenzuela H, Pace K, Cabrera P, White R, Porvari K, Kaija H, Pirkko V, Baum L. O-Glycosylation Regulates LNCaP Prostate Cancer Cell Susceptibility to Apoptosis Induced by Galectin-1. Cancer Research, 67: 6155-6162, 2007.

[39] Kvitsinadze N, Megrelishvili I, Davitashvili E, Solomonia R, Aleksidze N, Karazanashvili G. Modulatory effect of zinc on lipid peroxidation in mitochondria and microsomes of a human prostate tissue during various pathologies. Proc. Georg Acad. Sci. Biol. Ser. A. 32(2):319-23, 2006

[40] Appffel Ch. Nathanson I. Microsomal aspects of carcinogenesis and neoplasia. Medical Hypothesis 5(1): 23-52, 1979. 